\title{
Computational Comparison of CPDT to other Conjugated Linkers in Triarylamine- based Organic Dyes
}

\author{
Clàudia Climent and David Casanova*
}

\begin{abstract}
The use of the cyclopentadithiophene (cpdt) fragment to chemically link electron donor and acceptor groups has become a rather common procedure to design new organic dyes with enhanced light harvesting properties. The photo-to-current efficiencies obtained by sensitized solar cells with dyes incorporating the cpdt moiety are commonly improved with respect to other similar $\pi$-fragments as separators. In many cases, the advantages of $c p d t$ can be related to the larger extinction coefficients obtained. In this work we perform a detailed computational study of triarylamine-based organic dyes with the cyanoacrylic acid as the acceptor group and considering a variety of conjugated linkers with $c p d t$ as the reference case. The influence of slightly different linkers and donor groups in the computed excitation energies and oscillator strengths is discussed by means of molecular geometries and frontier orbitals. The structural characteristics imposed by cpdt compared to similar conjugated bridges are responsible for its larger computed oscillator strengths. The insertion of an ethylene unit between the donor group and the linker systematically reduces the energy gap to the first excited singlet state and yields larger oscillator strengths of the optical transition. These results could be very helpful in the quest of new organic dyes with improved properties as sensitizers in Grätzel cells.
\end{abstract}

Keywords: Charge transfer · Computational chemistry · Excited states · Grätzel cell · Organic dyes

\section{Introduction}

As an alternative to conventional semiconductor photovoltaic devices, dyesensitized solar cells (DSC) have been the object of active research in the past two decades since O'Regan and Grätzel reported the first promising conversion efficiency of $7.1 \% .^{[1]}$ The sensitizer plays a role of vital importance in DSC since it is responsible for the absorption of solar radiation and the subsequent electronic injection to the conduction band of the semiconductor (usually mesoporous $\mathrm{TiO}_{2}$ ). ${ }^{[2]}$ Traditionally, due to their considerable light-harvesting capacities, ruthenium complexes have been the most widely used dyes, ${ }^{[3]}$ but recently there has been an increasing interest in metal-free sensitizers. ${ }^{[4]}$ Organic molecules present several advantages over the popular transition metal compounds,

${ }^{\star}$ Correspondence: Dr. D. Casanova Departament de Química Física

Institut de Química Teòrica i Computacional (IQTCUB) Universitat de Barcelona

Martí i Franquès, 1-11, 08028 Barcelona, Spain

Tel.: +34 934039266

E-mail: davidcasanovacasas@ub.edu such as great diversity, relatively simple synthesis with reasonable costs, high extinction coefficients, and moderate environmental impact. ${ }^{[5]}$ Although currently the solar-to-electric power conversion efficiencies obtained with ruthenium-based dyes are superior to those obtained with organic dyes, ${ }^{[6]}$ the common donor- $\pi$-bridgeacceptor structure of the latter provides a feasible manner to design the molecular structure of the dye in order to achieve the desired photophysical properties. In this sense, computational calculations by means of quantum mechanical tools have been of great help to understand and rationalize the experimental observations, ${ }^{[7,8]}$ and in combination with experimental advances they could open new routes for improved efficiencies guiding the synthesis of new dyes in a much focalized and useful manner.

In this article we report on the computed photophysical properties of a series of D- $\pi$-A organic dyes with the bis(4methoxyphenylamino)phenyl unit and the cyanoacrylic acid as donor and acceptor groups, respectively, and with the commonly employed cyclopentadithiophene linker ${ }^{[9]}$ as the reference case. More concretely, this work focuses on understanding how small chemical modifications on the conjugated bridge and the donor group tune the light absorption properties of the dye. Variations in the computed excitation energies, oscillator strengths and charge transfer character (CT) of the optical ex- citation are discussed and rationalized in detail by means of the optimized molecular geometries and their electronic structure peculiarities.

\section{Computational Details}

Geometry optimizations for all studied organic sensitizers (Fig. 1) in the ground state have been performed with no symmetry restrictions within the density functional theory (DFT) methodology, with the $\omega$ PBEh long-range corrected (LC) density functional ${ }^{[10]}$ and the $6-31+\mathrm{G}(\mathrm{d})$ atomic basis set. The solvent effects were taken into account by the polarizable continuum model (PCM), ${ }^{[11]}$ considering acetonitrile as the solvent with 37.5 as the value of the static dielectric constant. The vertical excitation energies were calculated at these geometries by the same density functional with the time-dependent density functional theory (TDDFT) methodology within the Tamm-Dancoff approximation (TDA) ${ }^{[12]}$ and the 6-311+G(2d,2p) basis set. The Q-Chem program ${ }^{[13]}$ has been employed in all calculations.

\section{Results and Discussion}

The studied organic dyes follow the $D-\pi$-A pattern with the cyanoacrylic acid as the acceptor unit. As a reference, we compute and analyze the photophysical 
properties of the case with the bis(4-methoxyphenylamino)phenyl fragment as the donor group $\left(\mathrm{D}_{\mathrm{B}}\right)$ and the cyclopentadithiophene $(c p d t)$ unit as the conjugated linker. We study the role of several separators by replacing the $c p d t$ moiety with bithiophene $(b t)$, benzodithiobphene $(b d t)$ and dithienothiophene $(d t t)$. We also investigate the effect of replacing the benzene ring in $D_{B}$ chemically bonded to the linker by a thiophene unit, i.e. bis(4-methoxyphenylamino)thienyl $\left(\mathrm{D}_{\mathrm{T}}\right)$. In addition, we explore the consequences of inserting an ethylene fragment between the donor group and the linker for all the studied bridges. The set of analyzed molecules is shown in Fig. 1.

Several conformations are possible for each organic dye. Here, we take into account the isomerism regarding the relative cis (C) or trans (T) conformation of three pairs of double bonds between: (i) ethylene-linker, (ii) linker-acceptor and (iii) $\mathrm{C}=\mathrm{C}$ and $\mathrm{C}=\mathrm{O}$ in the acceptor (Fig. 2). Thus, a three-letter string describes all possible cases for each dye. The conformers of molecules without the ethylene unit are indicated by an $n$ at the first string position. Only the energetically preferred trans disposition between the two thiophene rings in the $b t$ linker is considered.

\section{Ground State Geometries}

Geometric particularities of molecular dyes can have a substantial influence on their electronic structure properties, ${ }^{[8,14]}$ and play a crucial role regarding their light-harvesting ability. Although the set of studied molecules has very similar structures, there are some geometrical differences, such as the length and planarity of the sensitizer, which might be important concerning their photophysical properties.

As a first approximation, the donoracceptor spatial separation induced by

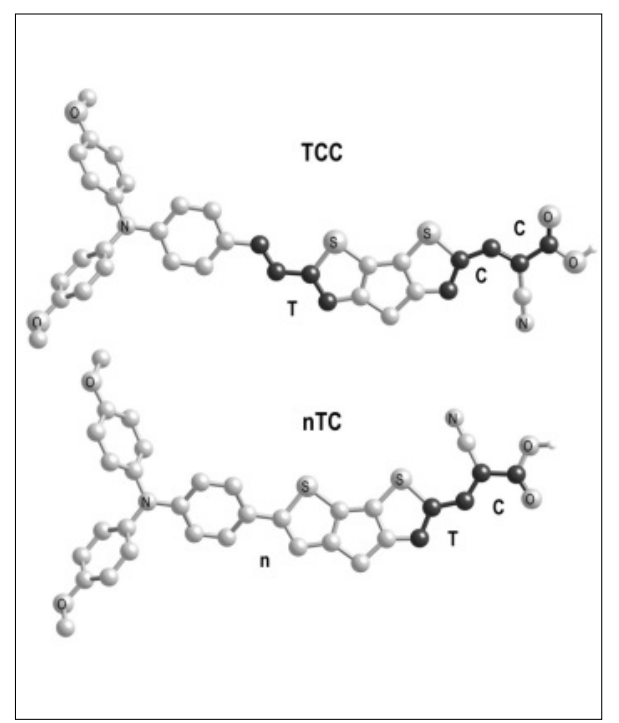

Fig. 2. Nomenclature employed in this work in order to distinguish between molecular conformers.

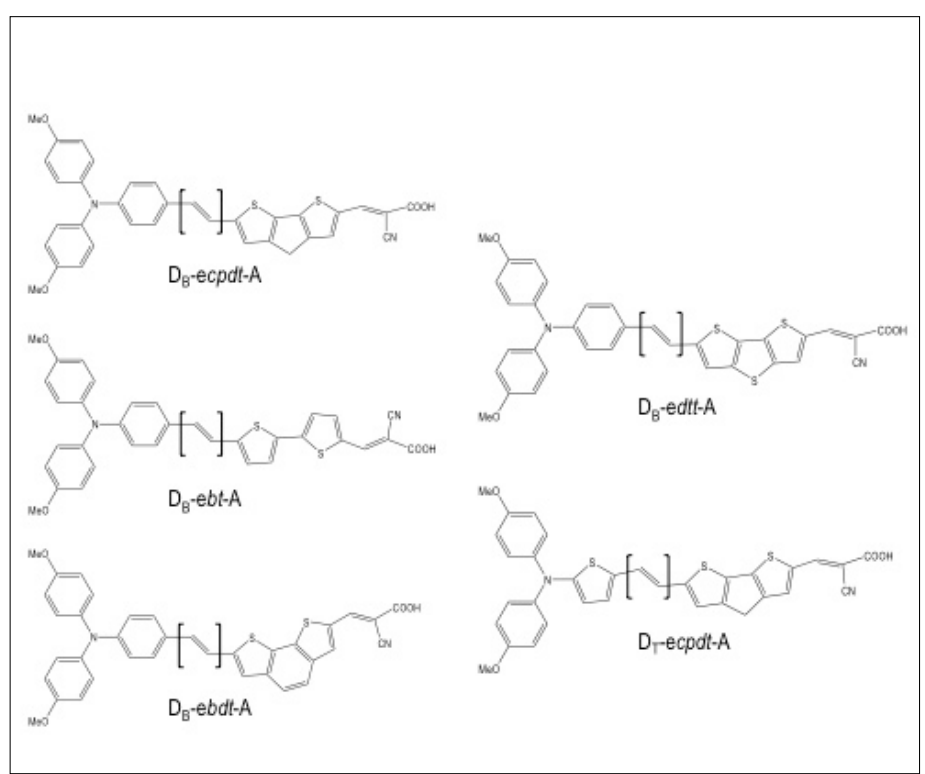

Fig. 1. Studied $D-\pi-A$ organic dyes with bis(4-methoxyphenylamino)phenyl $\left(D_{B}\right)$ or bis(4-methoxyphenylamino)thienyl $\left(\mathrm{D}_{\mathrm{T}}\right)$ as donor groups, the cyclopentadithiophene (cpdt), bithiophene (bt), benzodithiobphene $(b d t)$, dithienothiophene $(d t t)$ units as linkers, and the cyanoacrylic acid (A) as the electronic acceptor. The parentheses indicate two different possibilities, i.e. with (e prefix in the bridge acronym) and without the ethylene unit.

the linker, for example measured as the distance between the nitrogen atom in the donor unit and the carboxylic carbon atom of the acceptor group $\left(\mathrm{d}_{\mathrm{NC}}\right.$ in Fig. 3), can be associated to the hole/particle separation distance generated by the optical tran-

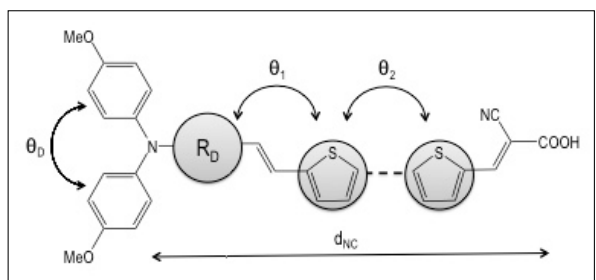

Fig. 3. General molecular pattern of the studied organic dyes with measured geometrical parameters: donor to acceptor separation $\left(\mathrm{d}_{\mathrm{NC}}\right.$ in $\AA$ ), and dihedral angles between the two methoxyphenyl rings of the donor $\left(\theta_{\mathrm{p}}\right)$, the adjacent rings between donor and linker $\left(\theta_{1}\right)$ and the two thiophenes in the the $\pi$-bridge $\left(\theta_{2}\right)$. sition. It is important to take into account not only the size of the linker between the two end groups, but the differences between molecular conformations as well. On average, the dyes with the ecpdt, ebt and edtt linkers present very similar donor to acceptor distances $\left(\mathrm{d}_{\mathrm{NC}} \sim 18.0 \AA\right)$, which are $\sim 0.5 \AA$ longer than the separation with ebdt. The donor-acceptor separation in $\mathrm{D}_{\mathrm{T}}$ ecpdt-A also decreases by $0.5 \AA$ with respect to $\mathrm{D}_{\mathrm{B}}$-ecpdt-A (Table 1). Evidently, the presence of the ethylene unit increases the separation. The $\mathrm{N}-\mathrm{C}$ distance in molecular dyes with ethylene is between 16.8 and $18.3 \AA$, while it is 2.0 to $2.5 \AA$ shorter without ethylene $\left(15.0 \leq \mathrm{d}_{\mathrm{NC}} \leq 15.8 \AA\right)$.

The molecular planarity of the studied chromophores is a key geometrical element, which regulates the electronic properties of the dye. It seems obvious to imagine that the degree of coplanarity between the donor and the linker must have a great

Table 1. Average structural parameters ( $\mathrm{d}_{\mathrm{NC}}$ in $\AA$ and all dihedrals in degrees) of the studied organic dyes optimized geometries in acetonitrile ${ }^{\mathrm{a}}$.

$\begin{array}{lcccc}\begin{array}{l}\text { bridge } \\ \text { ethylene }\end{array} & \mathrm{d}_{\mathrm{NC}} & \theta_{1} & \theta_{2} & \theta_{\mathrm{D}} \\ e c p d t & 18.0 & 4.9 & 0.1 & 60.4 \\ e b t & 18.0 & 7.1 & 6.8 & 60.8 \\ e b d t & 17.4 & 10.9 & 0.1 & 61.0 \\ e d t t & 17.9 & 7.3 & 0.0 & 61.1 \\ e c p d t^{b} & 17.4 & 6.0 & 0.0 & 69.5\end{array}$

no ethylene

$\begin{array}{llccc}c p d t & 15.7 & 26.9 & 0.1 & 62.3 \\ b t & 15.7 & 26.7 & 10.7 & 59.5 \\ b d t & 15.2 & 25.8 & 0.1 & 62.1 \\ d t t & 15.6 & 30.3 & 0.0 & 60.5 \\ c p d t^{b} & 15.3 & 19.6 & 0.3 & 66.7\end{array}$

${ }^{\mathrm{a} A}$ veraged values between all conformers of each molecule. ${ }^{\mathrm{b}} \mathrm{D}_{\mathrm{T}}$ donor group 
Table 2. Structural parameters $\left(\mathrm{d}_{\mathrm{NC}}\right.$ in $\AA$ and $\theta_{1}$ in degrees) and relative energies (kcal/mol) with respect to the most stable conformation for the studied conformers of $D_{B}$-ecpdt- $A$ and $D_{B}$-cpdt-A organic dyes optimized in acetonitrile.

$\begin{array}{lccc}\text { conformer } & \mathrm{d}_{\mathrm{NC}} & \theta_{1} & \Delta \mathrm{E} \\ \text { ethylene } & & & \\ C C C & 18.21 & 1.1 & 1.33 \\ C C T & 18.25 & 2.8 & 1.90 \\ C T C & 18.06 & 2.3 & 0.78 \\ C T T & 18.07 & 8.4 & 1.32 \\ T C C & 17.90 & 3.1 & 0.78 \\ T C T & 17.96 & 3.3 & 1.34 \\ T T C & 17.63 & 8.6 & 0.00 \\ T T T & 17.63 & 9.7 & 0.56 \\ \text { no ethylene } & & & \\ n C C & 15.77 & 26.8 & 0.73 \\ n C T & 15.82 & 26.8 & 1.26 \\ n T C & 15.59 & 26.5 & 0.00 \\ n T T & 15.60 & 27.4 & 0.50\end{array}$

impact on the donor-acceptor electronic coupling through the $\pi$-system of the bridge. In other words, the dihedral angle $\theta_{1}$ in Fig. 3 will determine to a large extent the conjugation of the molecule and the overlap between the $\pi$-system of the two ends. The ethylene unit connecting donor and linker groups relaxes the geometrical tension between rings, resulting in rather small $\theta_{1}$ angles. The molecular planarity is severely lost without the olefinic unit, and $\theta_{1}$ increases by about $20^{\circ}$ and $15^{\circ}$ for the $\mathrm{D}_{\mathrm{B}}$ and $\mathrm{D}_{\mathrm{T}}$ donors, respectively. In addition to the disposition between the donor and the conjugated bridge measured by $\theta_{1}$, it is also important to consider the planarity of the linker itself, i.e. the dihedral angle between the two thiophene rings $\left(\theta_{2}\right)$. For all the linkers where the two thiophenes cannot freely rotate, i.e. cpdt, $d t t$ and $b d t$, the bridge is perfectly planar $\left(\theta_{2}<0.4^{\circ}\right)$. On the contrary, if the rotation between the two thiophene rings is not constrained, i.e. $b t$, the linker prefers to break its planarity $\left(0.0<\theta_{2}<16.1^{\circ}\right)$ in order to avoid steric hindrance between rings, which reduces the $\pi$-conjugation of the molecule.

The two methoxyphenyl rings of the donor group are disposed out of the molecular plane defined by the linker and acceptor fragments, and there are no major differences in the dihedral angles between the two rings $\left(\theta_{D}\right.$ in Fig. 3) for all studied molecules. Therefore, this parameter is not expected to have a major influence on the relative photophysical properties of the dyes. The $\theta_{\mathrm{D}}$ angle ranges from $56^{\circ}$ to $65^{\circ}$ for all the cases with a phenyl ring in the $R_{D}$ position, and becomes a bit larger when the phenyl ring in $R_{D}$ is replaced by a thiophene unit $\left(\mathrm{D}_{\mathrm{T}}\right.$-ecpdt-A dye), with transition. indicate that the energetic cost of the trans to $\mathrm{cis}$ isomerization around the ethylene unit between the donor and the $\pi$-bridge is $0.5-0.8 \mathrm{kcal} / \mathrm{mol}$, while the linker-acceptor trans conformation is $0.6-0.8 \mathrm{kcal} / \mathrm{mol}$ more stable than the cis form. The cis configuration between the two double bonds in the A group is slightly more stable (0.5-0.6 $\mathrm{kcal} / \mathrm{mol}$ ) than the trans case. Hence, the TTC is the most stable conformer of the $\mathrm{D}_{\mathrm{B}}$-ecpdt-A family in acetonitrile solution.

The trends of the geometrical parameters and relative energies in Table 2 are not exclusive for the $c p d t$ linker, and very similar behaviors are obtained for the other studied molecules (Table A1 of the Appendix ${ }^{[15]}$, with small shifts in the absolute values already indicated by the differences in the averaged values of Table 1 .

\section{Vertical Transition to the Lowest Excited Singlet}

For all dyes in Fig. 1, the optical transition mainly corresponds to the electronic promotion from the HOMO, mostly located on the $\mathrm{D}_{\mathrm{B}}\left(\right.$ or $\left.\mathrm{D}_{\mathrm{T}}\right)$ group, to the LUMO, centered at the cyanoacrylic acid (A). The next most important contributions in the first excited singlet wavefunction come from the HOMO-1 to LUMO and HOMO to LUMO+1 configurations (Fig. 4).

The average vertical transition energy of the $\mathrm{D}_{\mathrm{B}}$-ecpdt-A dye in acetonitrile is computed to be $2.79 \mathrm{eV}$. In the ebt case, the HOMO-1 and the LUMO+1 are more involved in the $S_{0}$ to $S_{1}$ transition (Fig. 4). The larger participation of these higher energy contributions results in a small blue shift of the energy gap $(0.04-0.09 \mathrm{eV})$ with respect to the ecpdt dye. Excitation energies with the $e b d t$ and $e d t t$ linkers are 0.27 and $0.12 \mathrm{eV}$, respectively, larger than the ecpdt energies. The chemical change of the ecpdt $\pi$-bridge by $e b d t$ or $e d t t$ has a minor effect on the HOMO and the LUMO

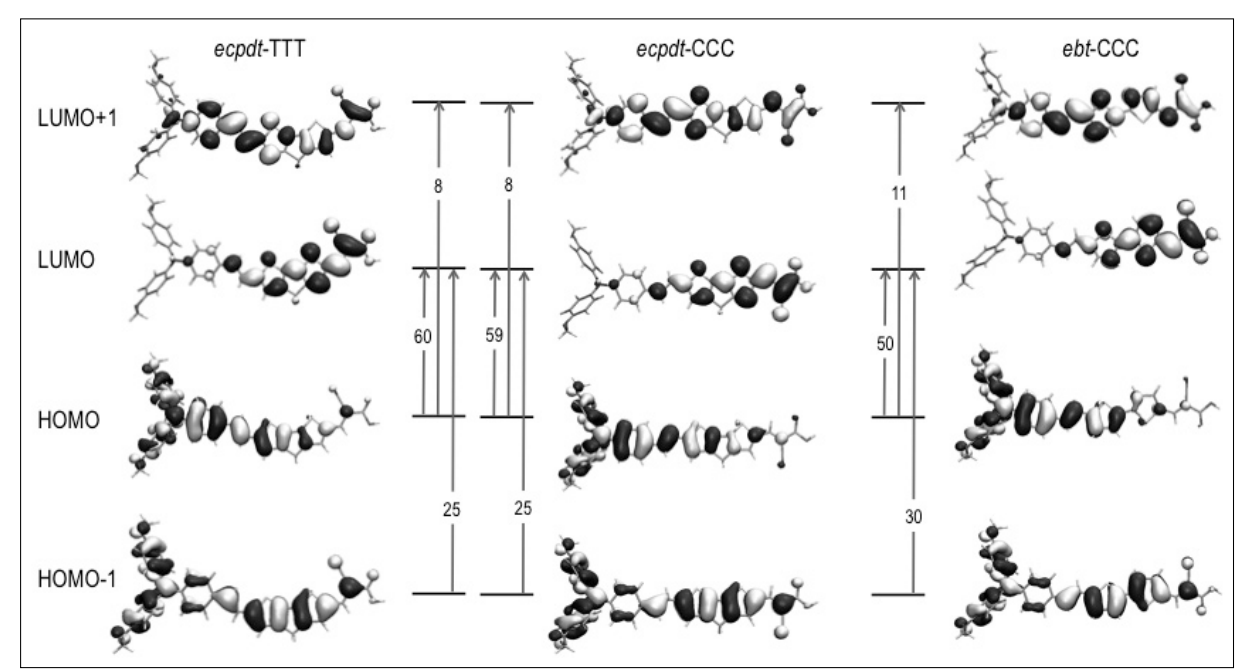

Fig. 4. Frontier molecular orbitals of the all trans (TTT) and all cis (CCC) $D_{B}$-ecpdt-A conformers and the all cis $D_{B}$-ebt-A dyes. Vertical arrows indicate the main contributions (in \%) of the $S_{0}$ to $S_{1}$ 
energies. The reason for this increase must be assigned to the HOMO-1 stabilization with the $e b d t$ and $e d t t$ linkers with respect to ecpdt (Table A2 of the Appendix ${ }^{[15]}$ ), which has a substantial participation in the transition (25-30\%) and is markedly located on the linker fragment. The substitution of benzene by thiophene in the donor group systematically reduces the excitation energy by $0.09-0.15 \mathrm{eV}$. This mutation mainly affects the HOMO, which becomes energetically higher with the fivemember ring $\left(\mathrm{D}_{\mathrm{T}}\right)$, while the LUMO and LUMO+1 are basically unaffected. Thus, the HOMO-LUMO gap (and LUMO+1) decreases. Transition energies for the dyes without the ethylene unit follow the same trends, although the loss of conjugation in all molecules with respect to the cases with ethylene systematically increases the electronic excitations by $0.1-0.2 \mathrm{eV}$. As shown in Table 3 for the ecpdt and cpdt linkers, the excitation energies remain constant for all molecular conformations. This behavior is also obtained for the conformers of the other dyes (Table A3 of the Appendix ${ }^{[15]}$ ).

The intensity of the optical transition can be revealed by means of the TDDFT dimensionless computed oscillator strengths $f$ from the ground state to the lowest excited singlet. In average, the ecpdt linker triggers the largest transition probabilities. The $\mathrm{D}_{\mathrm{B}}-e d t t-\mathrm{A}_{\text {and }} \mathrm{D}_{\mathrm{T}}$-ecpdt- $\mathrm{A}$ give rise to very similar values, which are just a little bit lower than in the $\mathrm{D}_{\mathrm{B}}$-ecpdt-A case. The presence of the ebt and ebdt linkers significantly lowers the oscillator strengths with respect to ecpdt, especially the latter one. To trace back the differences between $\pi$-linkers in the computed strengths it is important to bear in mind that $f$ is proportional to the square of the dipole moment integral between the ground and excited states. This integral directly depends on the charge separation created by the electronic transition; hence, it must be proportional to $\mathrm{d}_{\mathrm{NC}}$. This dependence becomes evident when comparing the values between conformers of the same dye (Tables 2 and 3 ). In addition, in order to obtain significant transition moments it is necessary to have a non-zero spatial overlap between the two states. In other words, the extension of the overlap between the molecular orbitals involved in the transition will also tune the magnitude of the oscillator strengths. In this sense, the planarity of the molecule (related to $\theta_{1}$ and $\theta_{2}$ dihedral angles) is expected to improve this overlap and increase $f$. Moreover, this overlap will be larger for linear molecules than for those cases with curved geometries. This effect is probably the reason for the differences between $\mathrm{D}_{\mathrm{B}}$ ebdt-A (curved) and $\mathrm{D}_{\mathrm{T}}$-ecpdt-A (linear) dyes (similar $\mathrm{d}_{\mathrm{NC}}$ and planarity with rather different oscillator strengths). The shorter molecular length and the loss of planarity

Table 3. Average ground to first excited singlet transition energies $\Delta \mathrm{E}$ (in eV), oscillator strengths $f$ and charge increment at the donor and acceptor fragments $\Delta Q$ (in electrons) for the different conformers of the $D_{B}$-ecpdt-A and $D_{B}-c p d t-A$ in acetonitrile.

\begin{tabular}{|c|c|c|c|c|}
\hline \multirow[t]{2}{*}{ conformer } & \multirow[t]{2}{*}{$\Delta \mathrm{E}$} & \multirow[t]{2}{*}{$f$} & \multicolumn{2}{|c|}{$\Delta \mathrm{Q}$} \\
\hline & & & Donor & Acceptor \\
\hline \multicolumn{5}{|l|}{ ethylene } \\
\hline$C C C$ & 2.79 & 2.70 & 0.12 & -0.16 \\
\hline$C C T$ & 2.80 & 2.72 & 0.13 & -0.16 \\
\hline$C T C$ & 2.79 & 2.57 & 0.12 & -0.15 \\
\hline$C T T$ & 2.80 & 2.58 & 0.13 & -0.15 \\
\hline$T C C$ & 2.79 & 2.55 & 0.13 & -0.15 \\
\hline$T C T$ & 2.79 & 2.58 & 0.13 & -0.15 \\
\hline$T T C$ & 2.78 & 2.34 & 0.13 & -0.15 \\
\hline$T T T$ & 2.78 & 2.34 & 0.13 & -0.15 \\
\hline \multicolumn{5}{|l|}{ no ethylene } \\
\hline$n C C$ & 2.95 & 2.19 & 0.16 & -0.19 \\
\hline$n C T$ & 2.96 & 2.21 & 0.16 & -0.19 \\
\hline$n T C$ & 2.94 & 2.04 & 0.16 & -0.18 \\
\hline$n T T$ & 2.95 & 2.05 & 0.16 & -0.18 \\
\hline
\end{tabular}

of the dyes without the ethylene fragment systematically reduce the transition probability.

In general, the transition Mulliken charges at the donor and the cyanoacrylic acid acceptor groups, $\Delta \mathrm{Q}$ in Table 4 , are of the same order for all molecules. The slight differences between dyes can be understood by how well localized the HOMOs and LUMOs (involved in the electronic transition) are in the donor and acceptor groups, respectively. Larger localizations will result in larger overall negative charge transferred to the cyanoacrylic acid. Similarly, molecules without the ethylene unit present a systematic increase of $\Delta \mathrm{Q}$. This behavior is qualitatively revealed by the slightly different spatial localization of the HOMO and LUMO orbitals for the $\mathrm{D}_{\mathrm{T}}$ ecpdt- $\mathrm{A}_{\text {and }} \mathrm{D}_{\mathrm{B}}-b d t-\mathrm{A}$ and the related dyes without the ethylene unit, respectively (Fig. 5). There are basically no differences in the computed $\Delta \mathrm{Q}$ between conformers of the same dye (Table 3 ).

\section{Conclusions}

In this work we have computationally explored the photophysical properties of a set of D- $\pi$-A organic dyes. The study focuses on the cyclopentadithiophene $(c p d t)$ unit as a conjugated bridge and how it influences the characteristics of the optical transition in comparison to other similar linkers. The differences in the calculated excitation energies and oscillator strengths of the studied dyes have been plainly rationalized by means of geometrical parameters related to the linearity and planarity of the molecules, which affect the relative energies of frontiers molecular orbitals and the electronic interaction between donor and acceptor $\pi$-systems. The results point to the reasons why cpdt yields, in general, larger extinction coefficients. The presence of an ethylene unit between the donor and linker fragments increases the number of $\pi$-electrons, the donor-acceptor separation and the molecular planarity, leading to systematically red shifted excitation energies and larger oscillator strengths, independently of the employed $\pi$-bridge.

\section{Acknowledgements}

We are very grateful to Prof. Michael Grätzel for his advice and guidance. We also want to thank Prof. Pere Alemany for his valuable comments and good suggestions concerning our original manuscript. This work was supported by the Spanish Ministerio de Economía y Competitividad (project CTQ201123862-C02-02) and by the Generalitat de Catalunya (project 2009SGR-1459). D. C. gratefully acknowledges the Ramón y Cajal program (RyC 2008-0223) for financial support.

Received: December 12, 2012

[1] B. O'Regan, M. Grätzel, Nature 1991, 353, 737.

[2] J.-H. Yum, E. Baranoff, S. Wenger, M. K Nazeeruddin, M. Grätzel, Energy Environ. Sci. 2011, 4, 842 .

[3] M. Grätzel, J. Photochem. Photobiol., A 2004 164, 3; M. K. Nazeeruddin, F. De Angelis, S. Fantacci, A. Selloni, G. Viscardi, P. Liska, S. Ito, B. Takeru, M. Grätzel, J. Am. Chem. Soc. 2005, 127, 16835; M. K. Nazeeruddin, P. Pechy, M. Grätzel, Chem. Commun. 1997, 1705.

[4] A. Mishra, M. K. R. Fischer, P. Bäuerle, Angew. Chem. Int. Ed. 2009, 48, 2474.

[5] A. Hagfeldt, G. Boschloo, L. Sun, L. Kloo, H. Pettersson, Chem. Rev. 2010, 110, 6595. 


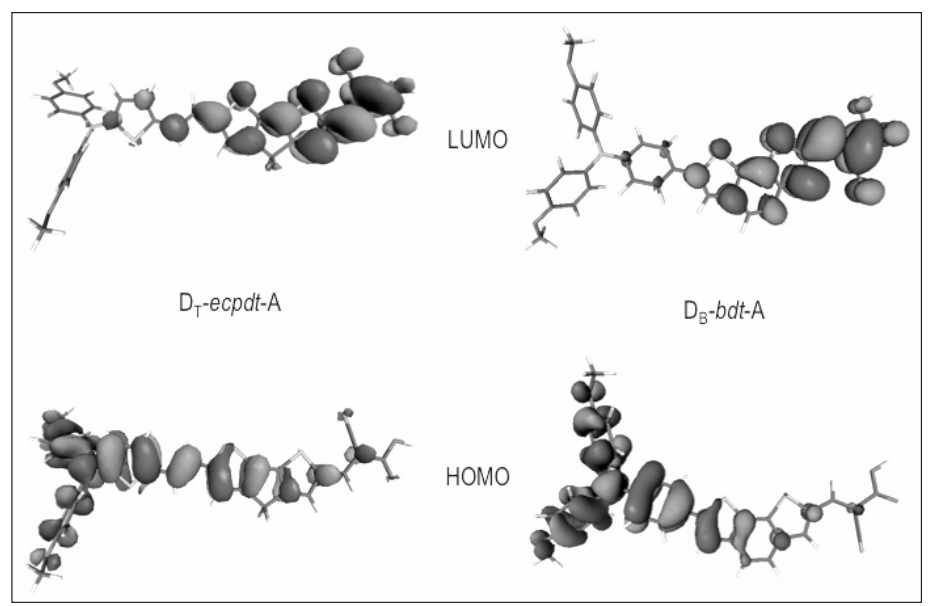

Fig. 5. HOMO (down) and LUMO (up) of $\mathrm{D}_{\mathrm{T}}$ ecpdt-A (left) and $\mathrm{D}_{\mathrm{B}}$ bdt-A (right) dyes.

Table 4. Average ground to first excited singlet vertical transition energies $\Delta \mathrm{E}$ (in eV), oscillator strengths $f$ and charge increment at the donor and acceptor fragments $\Delta Q$ (in electrons) of the $D_{B}$ bridge-A organic dyes in acetonitrile ${ }^{a}$

\begin{tabular}{lllll} 
bridge & $\Delta \mathrm{E}$ & $f$ & \multicolumn{2}{c}{$\Delta \mathrm{Q}$} \\
& & & Donor & Acceptor \\
ethylene & & & & \\
ecpdt & 2.79 & 2.55 & 0.13 & -0.15 \\
$e b t$ & 2.85 & 2.29 & 0.15 & -0.16 \\
$e b d t$ & 3.06 & 2.09 & 0.18 & -0.20 \\
$e d t t$ & 2.91 & 2.46 & 0.16 & -0.17 \\
$e c p d t^{\mathrm{b}}$ & 2.68 & 2.43 & 0.17 & -0.13 \\
no ethylene & & & & \\
$c p d t$ & 2.95 & 2.12 & 0.16 & -0.18 \\
$b t$ & 3.01 & 1.87 & 0.20 & -0.20 \\
$b d t$ & 3.21 & 1.61 & 0.23 & -0.26 \\
$d t t$ & 3.11 & 1.97 & 0.20 & -0.22 \\
$c p d t^{\mathrm{b}}$ & 2.79 & 1.99 & 0.21 & -0.16
\end{tabular}

${ }^{a}$ Averaged values between all conformers of each molecule. ${ }^{b} D_{T}$ donor group

[6] F. Gao, Y. Wang, J. Zhang, D. Shi, M. Wang, R. Humphry-Baker, P. Wang, S. M. Zakeeruddin, M. Grätzel, Chem. Commun. 2008, 2635; M. K. Nazeeruddin, T. Bessho, L. Cevey, S. Ito, C. Klein, F. De Angelis, S. Fantacci, P. Comte, P. Liska, H. Imai, M. Grätzel, J. Photochem. Photob., A 2007, 185, 331; Y. Chiba, A. Islam, Y. Watanabe, R. Komiya, N. Koide, L. Han, Jpn. J. Appl. Phys. 2006, 45, L638; S. Hwang, J. H. Lee, C. Park, H. Lee, C. Kim, C. Park, M.H. Lee, W. Lee, J. Park, K. Kim, N.-G. Park,
C. Kim, Chem. Commun. 2007, 4887; S. Ito, H. Miura, S. Uchida, M. Takata, K. Sumioka, P. Liska, P. Comte, P. Pechy, M. Grätzel, Chem. Commun. 2008, 5194; H. Im, S. Kim, C. Park, S.-H. Jang, C.-J. Kim, K. Kim, N.-G. Park, C. Kim, Chem. Commun. 2010, 46, 1335; H. Choi, I. Raabe, D. Kim, F. Teocoli, C. Kim, K. Song, J.-H. Yum, J. Ko, M. K. Nazeeruddin, M. Grätzel, Chem. Eur. J. 2010, 16, 1193.

[7] M. Pastore, E. Mosconi, F. De Angelis, M. Grätzel, J. Phys. Chem. C 2010, 114, 7205;
S. Meng, E. Kaxiras, M. K. Nazeeruddin, M. Graätzel, J. Phys. Chem. C 2011, 115, 9276; D. P. Hagberg, J.-H. Yum, H. Lee, F. De Angelis, T. Marinado, K. M. Karlsson, R. HumphryBaker, L. Sun, A. Hagfeldt, M. Grätzel, M. K. Nazeeruddin, J. Am. Chem. Soc. 2008, 130, 6259; D. Casanova, F. P. Rotzinger, M. Grätzel, J. Chem. Theory Comput. 2010, 6, 1219; D. P. Hagberg, T. Marinado, K. M. Karlsson, K. Nonomura, P. Qin, G. Boschloo, T. Brinck, A Hagfeldt, L. Sun, J. Org. Chem. 2007, 72, 9550.

[8] D. Casanova, ChemPhysChem 2011, 12, 2979.

[9] R. Li, J. Liu, N. Cai, M. Zhang, P. Wang, J. Phys. Chem. B 2010, 114, 4461; D.-Y. Chen, Y.Y. Hsu, H.-C. Hsu, B.-S. Chen, Y.-T. Lee, H. Fu, M.-W. Chung, S.-H. Liu, H.-C. Chen, Y. Chi, P.-T. Chou, Chem. Commun. 2010, 46, 5256; S. Van Mierloo, P. J. Adriaensens, W. Maes, L. Lutsen, T. J. Cleij, E. Botek, B. Champagne, D. J. Vanderzande, J. Org. Chem. 2010, 75, 7202; Y. Bai, J. Zhang, D. Zhou, Y. Wang, M. Zhang, P. Wang, J. Am. Chem. Soc. 2011, 133, 11442; M. Xu, D. Zhou, N. Cai, J. Liu, R. Li, P. Wang, Energy Environ. Sci. 2011, 4, 4735; X. Cheng, S. Sun, M. Liang, Y. Shi, Z. Sun, S. Xue, Dyes Pigm. 2012, 92, 1292.

[10] M. A. Rohrdanz, K. M. Martins, J. M. Herbert, J. Chem. Phys. 2009, 130, 54112 .

[11] M. Cossi, N. Rega, G. Scalmani, V. Barone, $J$. Comput. Chem. 2003, 24, 669.

[12] S. Hirata, M. Head-Gordon, Chem. Phys. Lett. 1999, 314, 291

[13] Y. Shao, L. F. Molnar, Y. Jung, J. Kussmann, C. Ochsenfeld, S. T. Brown, A. T. B. Gilbert, L. V. Slipchenko, S. V. Levchenko, D. P. O'Neill, R. A. DiStasio Jr, R. C. Lochan, T. Wang, G. J. O. Beran, N. A. Besley, J. M. Herbert, C. Y. Lin, T. V. Voorhis, S. H. Chien, A. Sodt, R. P. Steele, V. A. Rassolov, P. E. Maslen, P. P. Korambath, R. D. Adamson, B. Austin, J. Baker, E. F. C. Byrd, H. Dachsel, R. J. Doerksen, A. Dreuw, B. D. Dunietz, A. D. Dutoi, T. R. Furlani, S. R. Gwaltney, A. Heyden, S. Hirata, C.-P. Hsu, G. Kedziora, R. Z. Khalliulin, P. Klunzinger, A. M. Lee, M. S. Lee, W. Liang, I. Lotan, N. Nair, B. Peters, E. I. Proynov, P. A. Pieniazek, Y. M. Rhee, J. Ritchie, E. Rosta, C. D. Sherrill, A. C. Simmonett, J. E. Subotnik, H. L. W. Iii, W. Zhang, A. T. Bell, A. K. Chakraborty, Phys. Chem. Chem. Phys. 2006, 8, 3172.

[14] M. Xu, S. Wenger, H. Bala, D. Shi, R. Li, Y. Zhou, S. M. Zakeeruddin, M. Grätzel, P. Wang, J. Phys. Chem. C 2009, 113, 2966; R. Li, X Lv, D. Shi, D. Zhou, Y. Cheng, G. Zhang, P. Wang, J. Phys. Chem. C 2009, 113, 7469; S. Kim, J. K. Lee, S. O. Kang, J. Ko, J. H. Yum, S. Fantacci, F. De Angelis, D. Di Censo, M. K. Nazeeruddin, M. Grätzel, J. Am. Chem. Soc. 2006, 128, 16701; M. Wang, M. Xu, D. Shi, R. Li, F. Gao, G. Zhang, Z. Yi, R. Humphry-Baker, P. Wang, S. M. Zakeeruddin, M. Grätzel, $A d v$. Mater. 2008, 20, 4460

[15] Supplementary material available on $w w w$. ingentaconnect.com/content/scs/chimia. 